\title{
Magnetic Resonance Imaging of the Small Bowel in Crohn's Disease: A Systematic Review and Meta-Analysis
}

\author{
Osman Ahmed, David Mario Rodrigues, and Geoffrey C. Nguyen \\ Mount Sinai Hospital Centre for Inflammatory Bowel Disease, University of Toronto, Toronto, ON, Canada M5G 1X5 \\ Correspondence should be addressed to Geoffrey C. Nguyen; geoff.nguyen@utoronto.ca
}

Received 5 May 2015; Accepted 1 July 2015

Copyright (C) 2016 Osman Ahmed et al. This is an open access article distributed under the Creative Commons Attribution License, which permits unrestricted use, distribution, and reproduction in any medium, provided the original work is properly cited.

\begin{abstract}
Introduction. Crohn's disease is most commonly found in the terminal ileum and colonic region. Magnetic resonance has become a useful modality for assessing small bowel activity. In this study, we performed a systematic review and meta-analysis on the use of MR in detecting small bowel activity as well as extramural complications in Crohn's patients. Methods. Two independent reviewers sorted through articles until October 2, 2014. We included both studies providing raw data for pooling and studies without raw data. Sensitivity, specificity, likelihood ratios, and 95\% confidence intervals were calculated for each study. Results. There were 27 included studies, of which 19 were included in the pooled analysis. Pooled analysis of the 19 studies (1020 patients) with raw data revealed a sensitivity of 0.88 ( $95 \%$ CI 0.86 to 0.91 ) and specificity was 0.88 ( $95 \%$ CI 0.84 to 0.91 ). In regard to detecting stenosis, pooled sensitivity was 0.65 (95\% CI 0.53 to 0.76 ) and specificity was 0.93 (95\% CI 0.89 to 0.96 ). Conclusion. MR imaging provides a reliable alternative in detecting small bowel activity in patients with Crohn's disease. Its advantages include high diagnostic accuracy and no radiation exposure while its disadvantages include high cost and limited availability.
\end{abstract}

\section{Introduction}

Crohn's disease is an inflammatory bowel disease that may present with systemic symptoms such as fever, fatigue, and weight loss, as well as abdominal symptoms including pain and diarrhea [1]. Unlike ulcerative colitis, Crohn's disease can manifest anywhere in the gastrointestinal tract, though it most commonly affects the terminal ileum and colon. It is estimated that almost $50 \%$ of patients with Crohn's disease will have involvement of the small bowel, and up to $30 \%$ will have small bowel involvement only [2]. Crohn's disease is most often diagnosed by a combination of clinical features, endoscopy, and histopathology. Although the exact pathogenesis is still unclear, the disease manifests itself endoscopically as focal ulcerations with skip lesions (normal appearing bowel along with areas of inflammation) [1].

Recently, there has been an increase in the use of imaging modalities in assisting the diagnosis of Crohn's disease as well as assessing disease severity. Conventional enteroclysis, ultrasound (US), computed tomography (CT), and magnetic resonance (MR) imaging have all been used to detect inflammation in the bowel $[3,4]$. The use of imaging for diagnosing small bowel activity has become even more relevant since traditional methods of diagnosis (e.g., endoscopy) are not able to visualize the small bowel reliably, and up to $10 \%$ of patients will have small bowel involvement not amenable to visualization by endoscopy [1]. Additionally, endoscopic methods of assessment carry the risk of procedural complications and can cause patient discomfort [5].

Multiple studies have investigated the use of imaging to diagnose small bowel activity in Crohn's patients. Although the use of conventional enteroclysis and CT have shown good diagnostic accuracy, they are limited by exposure to ionizing radiation [6]. Ultrasound is a nonradiating form of imaging but is limited because image quality is dependent on technician expertise [7].

Magnetic resonance has become a useful modality for assessing small bowel activity in Crohn's disease, with multiple studies showing great sensitivity and specificity. The use of enteral contrast agents using MR enterography protocols has allowed for better distention as well as visualization of the small bowel [8]. Previous studies and reviews have looked at the use of MR in Crohn's disease; however these studies were limited in only assessing small bowel activity or extraluminal complications $[9,10]$. Multiple new studies have since emerged looking at this field. In this study, we 
performed a systematic review and meta-analysis on the use of MR in detecting small bowel activity as well as intraand extraluminal complications in Crohn's patients. We also determined whether the use of MR enteroclysis, a recent method of administrating contrast, yields any advantages over conventional MR enterography.

\section{Materials and Methods}

2.1. Search Strategy. We performed a comprehensive search strategy with the use of electronic databases including MEDLINE, EMBASE, CINAHL, and Cochrane Central Register of Controlled Trials. All relevant articles published until October 2, 2014, were included. Our search strategy included individual and combinations of relevant terms including "Crohn's", "inflammatory bowel disease", and "magnetic resonance" (see Supplementary Table 1 in Supplementary Material available online at http://dx.doi.org/10.1155/2016/7857352 for comprehensive search terms used). References of selected articles and previously published review articles were also manually searched to identify relevant studies.

2.2. Study Selection and Data Extraction. Our inclusion criterion was any study that compared the use of magnetic resonance to diagnose small bowel activity in Crohn's disease. We used as a reference standard surgery, ileocolonoscopy, and/or histopathology individually or as components of a global consensus. Small bowel was defined as any region distal to the pylorus up until the area proximal to the ileocecal junction. Authors of studies that combined small and large bowel data were contacted in order to obtain data for small bowel only. If we received no response, the study was excluded from the review. Studies which did not provide per-patient raw data (in terms of true positive, true negative, false positive, and false negative values) for the small bowel were also contacted for that information. If we received no response from the authors, they were still included in the review (including studies with only per-segment raw data) but excluded from the metaanalysis. Studies that comprised pediatric populations, were non-English, or used a reference standard that did not include surgery, ileocolonoscopy, or histopathology were excluded. Abstracts, conference presentations, and posters were also excluded.

All retrieved studies were sorted independently by two reviewers (Osman Ahmed and David Mario Rodrigues). Any disagreements were resolved either by consensus or by a third reviewer. Data from all selected studies was extracted independently by the same two reviewers (Osman Ahmed and David Mario Rodrigues). They followed a data extraction form that was created a priori and included study characteristics (year, country, age, gender, number of patients, type of study, reference standard, patient population, and location studied) and imaging characteristics (enterography versus enteroclysis, magnetic field strength, oral and intravenous contrast, bowel preparation, radiologist's experience, and time interval between MR and reference standard). Finally, specific values were extracted or calculated for studies that provided per-patient raw data (true positive, true negative, false positive, and false negative). For studies that included per-patient values for different segments of the small bowel, only the most distal part of the small bowel was included as this is the area most commonly affected by Crohn's disease.

Assessment of risk of bias, quality, and applicability was performed by using the Quality Assessment of Diagnostic Accuracy Studies (QUADAS-II) tool developed for diagnostic studies [11]. Studies with scores greater than 9 were categorized as low-risk.

2.3. Statistical Analysis. For studies that did not provide raw data, a summary of the results was presented for small bowel activity using sensitivity and specificity values. For studies providing raw data, $2 \times 2$ contingency tables were created using the following variables (true positive, true negative, false positive, and false negative). Statistical analysis was performed with use of Meta-DiSc version 1.4 (J. Zamora, A. Muriel, and V. Abraira Meta-DiSc for Windows, XI Cochrane Colloquium, Barcelona, 2003) software. Sensitivity, specificity, likelihood ratios, and 95\% confidence intervals were calculated for each study. Figures for forest plots and summary receiver-operating characteristic (ROC) curves were also constructed using the software, while the area under the curve (AUC) was calculated. For pooled analysis, 0.5 was added to all cells that contained a value of 0 in order to include all studies in the analysis. Heterogeneity was assessed using the $I^{2}$ test.

\section{Results}

The initial search yielded 3981 studies. These studies were initially sorted by title yielding 332 studies, which were then limited to 29 studies based on abstract review. After retrieving the full articles and contacting authors for missing information, only 27 studies met the inclusion criteria (Supplementary Figure 1). Of the 27 included studies, 19 provided sufficient raw data to be included in the pooled analysis; eight studies provided only summaries of the results [12-38]. All studies had a QUADAS-II score equal to or greater than 9, indicating low-risk.

3.1. Study Characteristics. Individual study characteristics are reported in Tables 1 and 2. A total of 19 studies with 1020 patients were included in the meta-analysis. Eight studies with a total of 650 patients were only included in the systematic review (Table 3) [12-38].

There were 17 prospective studies $[12,15-17,19,21-$ $23,26-29,31,32,34,35,38], 4$ retrospective studies [25, $30,33,37]$, and one study [36] that had both retrospective and prospective components. An additional 5 studies were unclear in regard to the type of study $[13,14,18,20,24]$. In regard to patient population, 13 out of the 27 studies involved patients with established Crohn's disease [12, 14-17, 24, 26$30,36-38]$; 3 had only suspected CD [20, 21, 35]; and 11 had either suspected or established CD $[13,18,19,22,23,25,28,31-$ 34]. Most prospective studies used consecutive patients to limit selection bias. Study characteristics for all studies are summarized in Table 1.

In regard to imaging characteristics, most studies used a magnetic field strength of $1.5 \mathrm{~T}$, with 2 studies using $1.0 \mathrm{~T}$ 


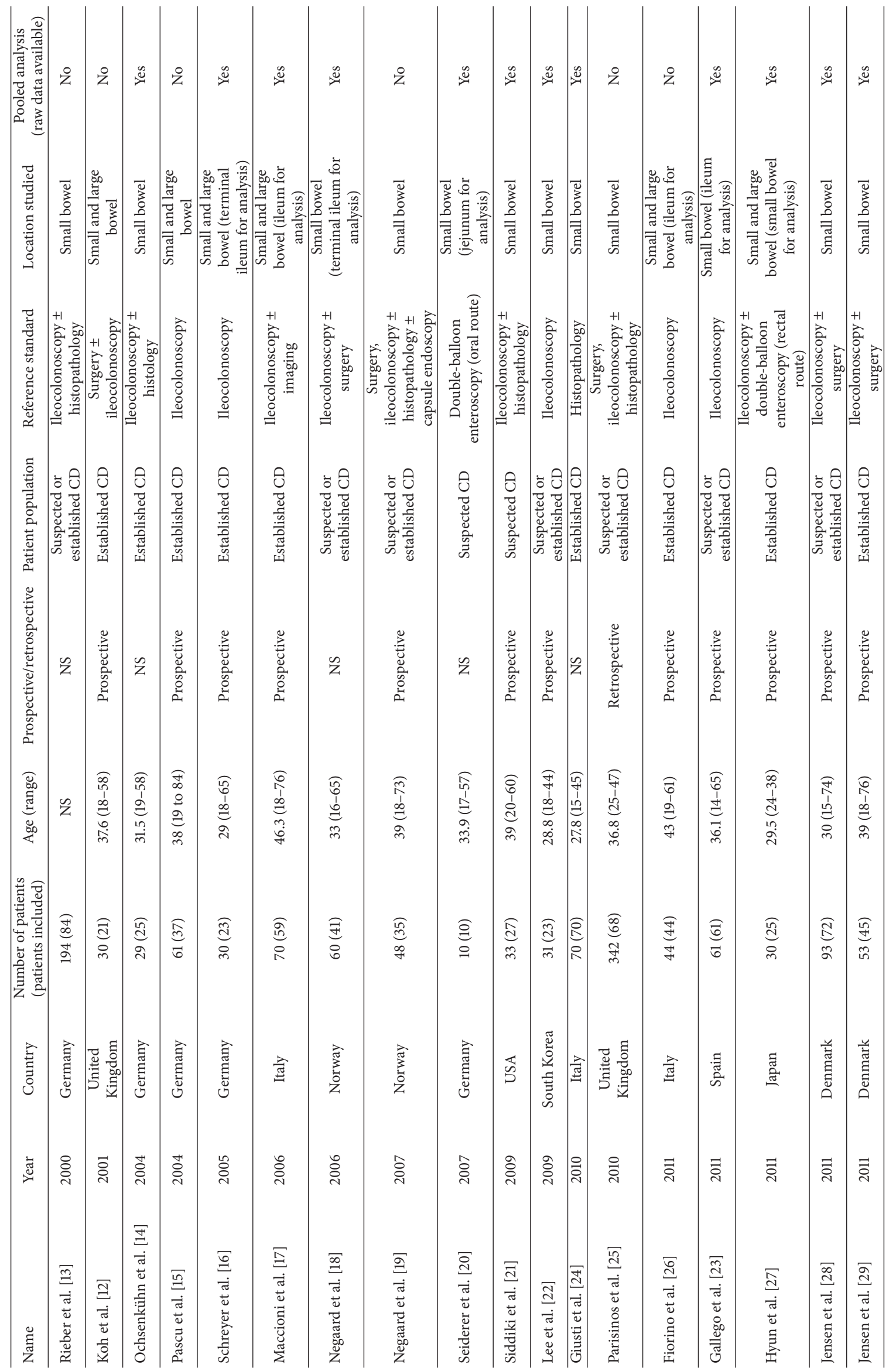




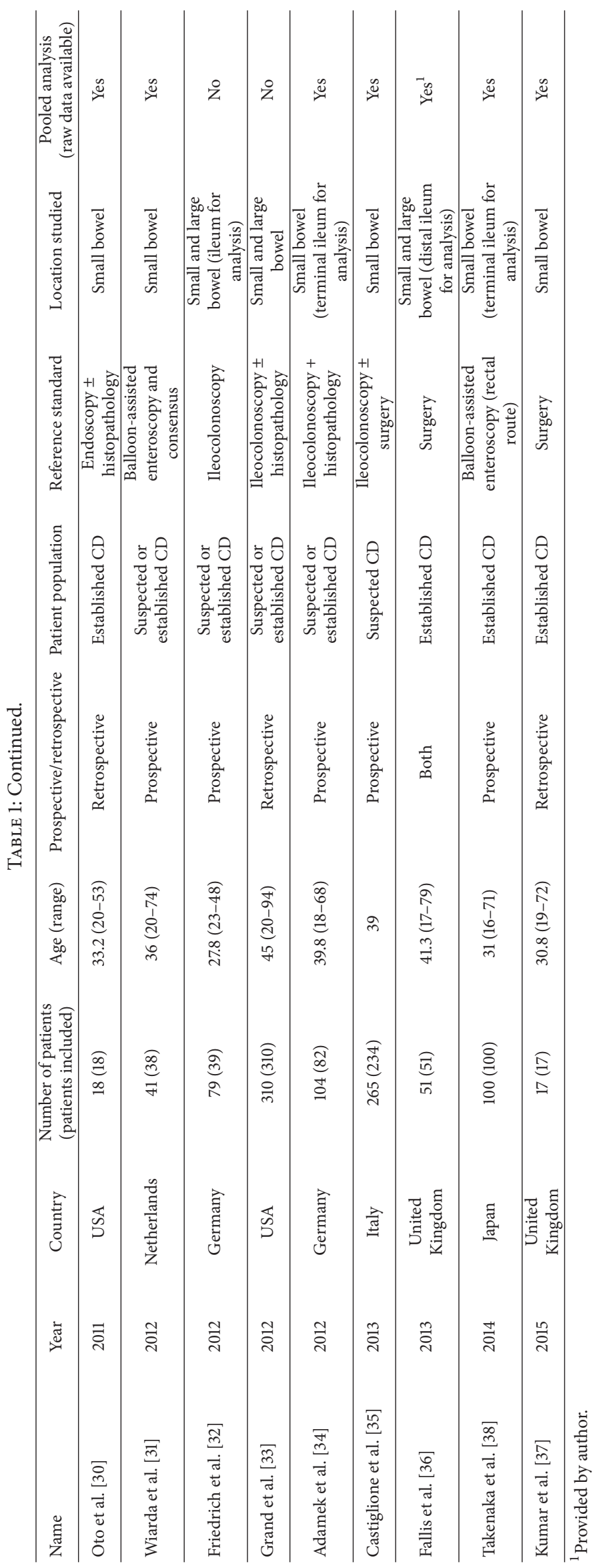




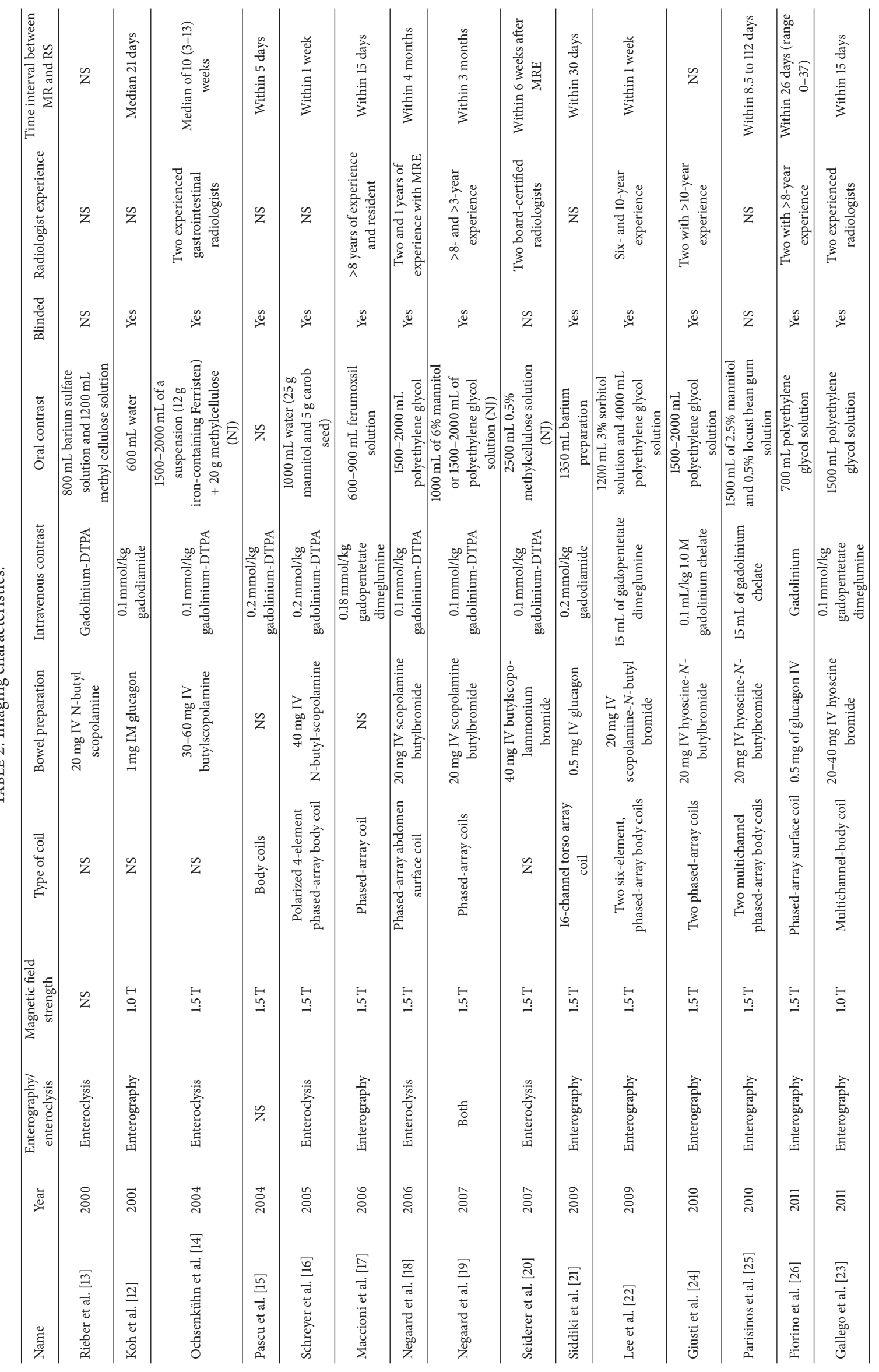




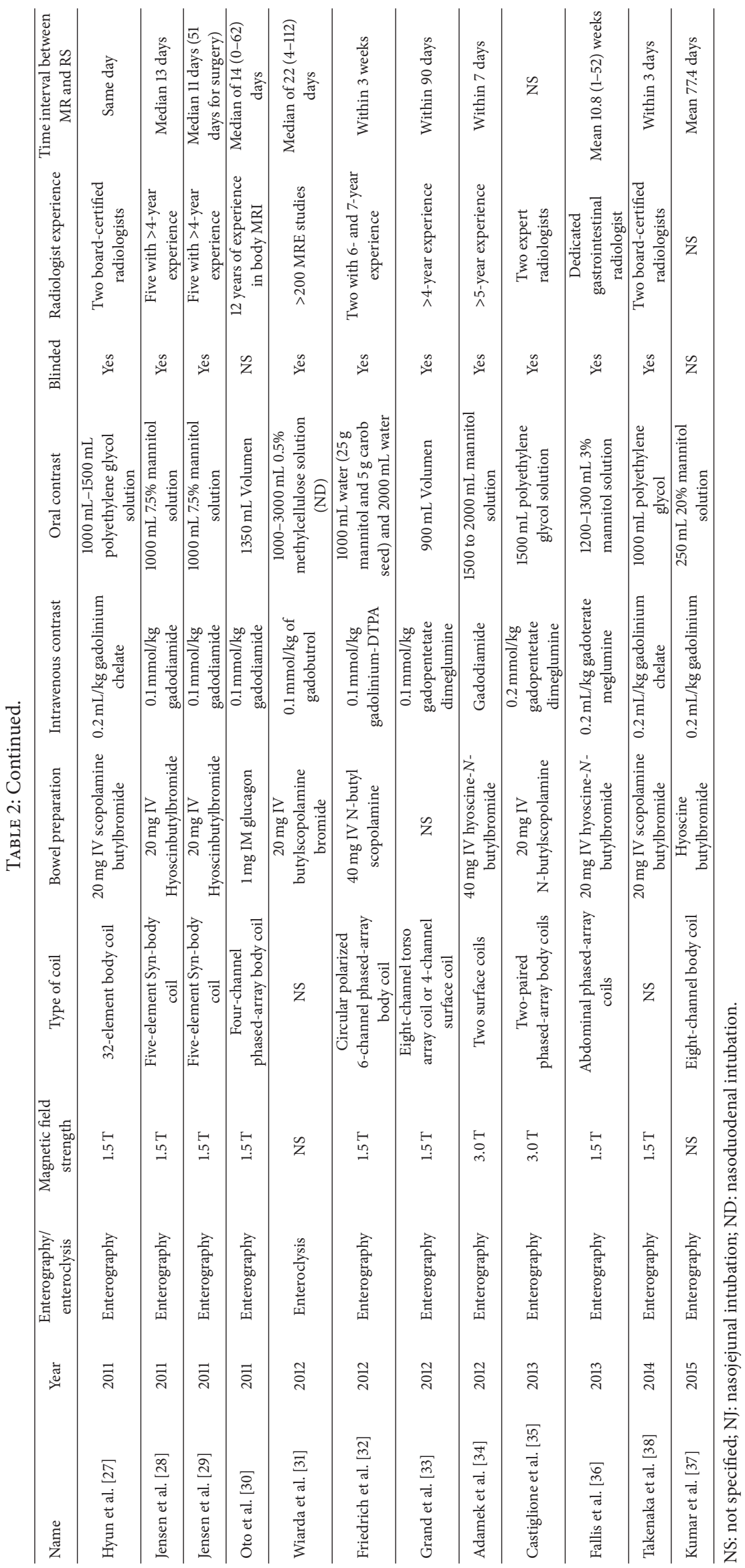


TABLE 3: Results (of nonpooled studies).

\begin{tabular}{lccl}
\hline Name & Year & $\begin{array}{c}\text { Number of patients } \\
\text { (number of patients included in analysis) }\end{array}$ & Results \\
\hline Rieber et al. [13] & 2000 & $194(84)$ & $\begin{array}{l}\text { Sensitivity and specificity of 95.2\% and 92.6\% in } \\
\text { terminal ileum }\end{array}$ \\
\hline Koh et al. [12] & 2001 & $30(21)$ & $\begin{array}{l}\text { Sensitivity and specificity of } 89 \% \text { and } 67 \% \text { in terminal } \\
\text { ileum }\end{array}$ \\
\hline Pascu et al. [15] & 2004 & $61(37)$ & $\begin{array}{l}\text { Per-segment sensitivity and specificity of 56\% and 73\% } \\
\text { in terminal ileum }\end{array}$ \\
\hline Negaard et al. [19] & 2007 & $48(35)$ & $\begin{array}{l}\text { Sensitivity and specificity of } 88 \% \text { and } 89 \% \text { for MRI with } \\
\text { OS, and } 88 \% \text { and } 84 \% \text { for MR enteroclysis }\end{array}$ \\
\hline Parisinos et al. [25] & 2010 & $342(68)$ & Sensitivity and specificity of $85.1 \%$ and $85.71 \%$ in ileum \\
\hline Fiorino et al. [26] & 2011 & $44(44)$ & Sensitivity and specificity of $93 \%$ and $81 \%$ in ileum \\
\hline Friedrich et al. [32] & 2012 & $79(39)$ & $\begin{array}{l}\text { Sensitivity and specificity of } 72 \% \text { and } 87 \% \text { in terminal } \\
\text { ileum without rectal enema; } 100 \% \text { and } 74 \% \text { in terminal } \\
\text { ileum with rectal enema }\end{array}$ \\
\hline Grand et al. [33] & 2012 & $\begin{array}{l}\text { Sensitivity and specificity of } 85 \% \text { and } 79 \% \text { in distal } \\
\text { ileum }\end{array}$ \\
\hline
\end{tabular}

$[12,23]$ and 2 studies using $3.0 \mathrm{~T}[34,35]$. Three studies did not mention the magnetic field strength used [13, 31, 37]. Six of the 27 studies used enteroclysis as a method of introducing oral contrast $[13,14,16,18,20,31]$, while 19 studies used standard enterography. One study used both enterography and enteroclysis [19], while 1 study did not mention how oral contrast was given [15]; neither of these studies were included in the meta-analysis. Radiologist experience with abdominal $\mathrm{MR}$ and time interval between MR and the reference standard varied widely between the studies (Table 2).

In regard to disease activity, unless otherwise specified below, we considered positive small bowel activity to be when the individual study considered the disease active (no specific parameters were used). Maccioni et al. [17] provided raw data for both T1-weighted and T2-weighted imaging. We chose to include $\mathrm{T} 2$-weighted results as they have been shown previously to be more accurate for small bowel activity [39]. Oto et al. selected for patients with active disease and thus had no results for specificity [30]. Because Seiderer et al. used an anterograde endoscopic approach, the jejunum was used for analysis as very few patients had their terminal ileum intubated [20]. For Adamek et al., we used histopathology as the reference standard rather than ileocolonoscopy (both were provided) [34]. Alternatively, for Siddiki et al., we used ileocolonoscopy as the reference standard since not as many patients had histopathology results [21]. For Kumar et al., we used bowel thickening as representative of small bowel activity [37]. Jensen et al. published two studies in 2011. Because there was no overlap in the study populations, both were included in our meta-analysis $[28,29]$.

3.1.1. Nonpooled Studies Summary. Of the 8 studies which were not included in the pooled analysis, by far the largest was Grand et al. with 310 patients (out of 650 total patients) [33]. Of these, 162 underwent MR and endoscopy within 30 days and the per-patient analysis for the distal ileum revealed a sensitivity of $85 \%$ and a specificity of $79 \%$ in diagnosing Crohn's disease activity. The results of the remaining studies are summarized in Table 3.

3.2. Per-Patient Pooled Analysis. Forest plots for the sensitivity, specificity, and sROC for the use of MR in diagnosing small bowel Crohn's disease activity are presented (Figure 1, Supplementary Figure 2). Pooled analysis of the 19 studies with raw data revealed a sensitivity of 0.88 (95\% CI 0.86 to 0.91 ) with a heterogeneity of $\chi^{2}=80.38$ and $I^{2}$ of $77.6 \%$ (Figure 1 ). The pooled specificity was 0.88 (95\% CI 0.84 to 0.91 ) with a heterogeneity of $\chi^{2}=55.11$ and $I^{2}$ of $67.3 \%$ (Figure 1 ). Using a random effects model, the positive likelihood ratio was 5.2 (95\% CI 2.62 to 10.29 ) and the negative likelihood ratio was 0.17 (95\% CI 0.11 to 0.27) (Supplementary Figure 3). Using Moses' constant linear model, we were able to construct an sROC with an AUC of 0.93 (Supplementary Figure 2). As expected, most values reside in the left upper corner, suggesting high sensitivity and specificity.

3.3. Subgroup Analysis. Analysis of only prospective studies revealed a pooled sensitivity of 0.89 (95\% CI 0.86 to 0.92$)$ and a pooled specificity of 0.90 ( $95 \%$ CI of 0.86 to 0.93 ) (Figure 2). Five studies used enteroclysis as the method of administrating oral contrast $[14,16,18,20,31]$. Pooled analysis of these 5 studies gave a sensitivity of 0.84 ( $95 \%$ CI of 0.74 to 0.91 ) and a pooled specificity of 0.89 (95\% CI of 0.78 to 0.96$)$ as demonstrated in the forest plots (Figure 3 ).

3.4. Extramural Complications. We identified three extramural complications a priori (stenosis, fistula, and abscess). However, only two studies (Fallis et al. and Kumar et al.) $[36,37]$ provided raw data for analysis for fistulas and abscesses. Consequently, no pooled analysis was done for these complications. We conducted a pooled analysis and constructed forest plots for 6 studies that provided data for 


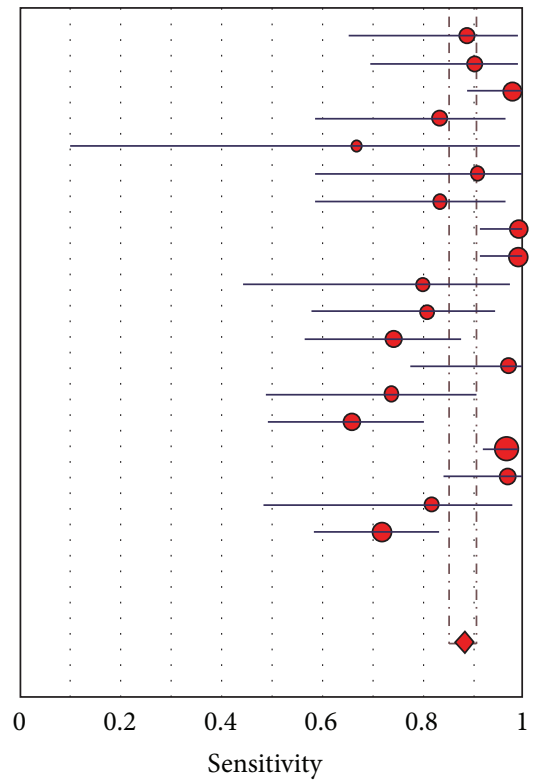

(a)

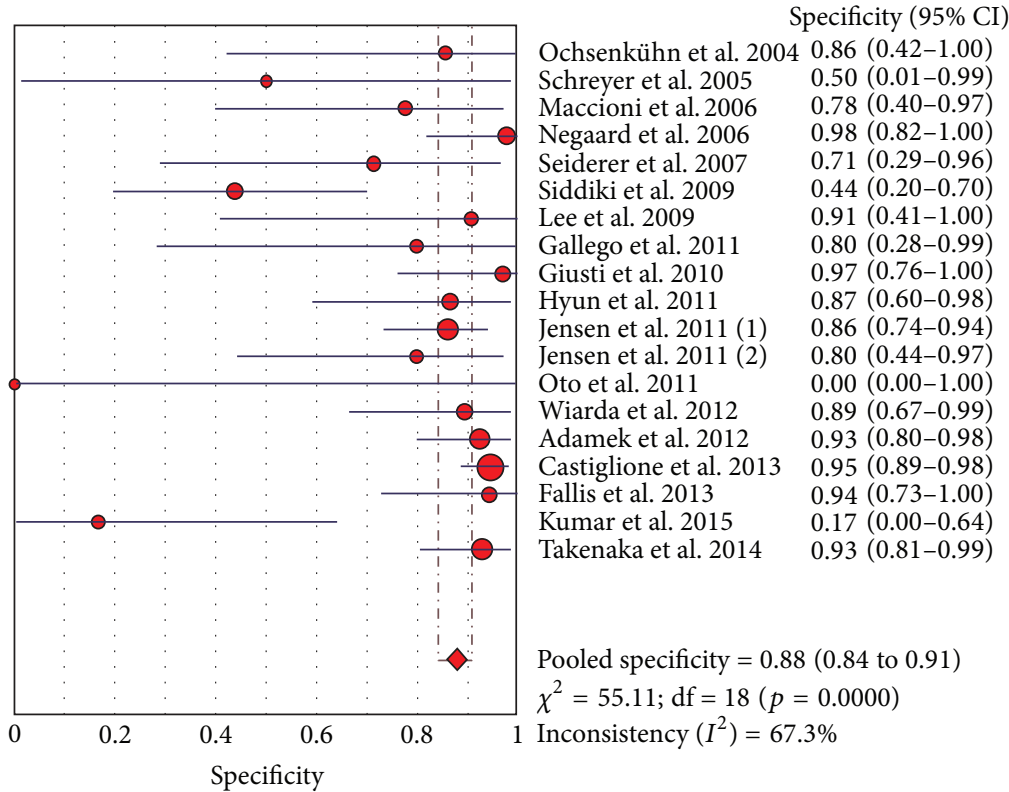

(b)

Ochsenkühn et al. 20040.89 (0.65-0.99)

Schreyer et al. $2005 \quad 0.90(0.70-0.99)$

Maccioni et al. $2006 \quad 0.98(0.89-1.00)$

Negaard et al. $2006 \quad 0.83(0.59-0.96)$

Seiderer et al. $2007 \quad 0.67(0.09-0.99)$

Siddiki et al. $2009 \quad 0.91(0.59-1.00)$

Lee et al. $2009 \quad 0.83(0.59-0.96)$

Gallego et al. $2011 \quad 0.99(0.92-1.00)$

Giusti et al. $2010 \quad 0.99(0.92-1.00)$

Hyun et al. $2011 \quad 0.80(0.44-0.97)$

Jensen et al. 2011 (1) $0.81(0.58-0.95)$

Jensen et al. 2011 (2) $0.74(0.57-0.88)$

Oto et al. $2011 \quad 0.97(0.77-1.00)$

Wiarda et al. $2012 \quad 0.74(0.49-0.91)$

Adamek et al. $2012 \quad 0.66(0.49-0.80)$

Castiglione et al. $2013 \quad 0.97(0.92-0.99)$

Fallis et al. $2013 \quad 0.97(0.84-1.00)$

Kumar et al. $2015 \quad 0.82(0.48-0.98)$

Takenaka et al. $2014 \quad 0.72(0.58-0.83)$

Pooled sensitivity $=0.88$ ( 0.86 to 0.91$)$

$\chi^{2}=80.38 ; \mathrm{df}=18(p=0.0000)$

Inconsistency $\left(I^{2}\right)=77.6 \%$

$0.50(0.01-0.99)$

Maccioni et al.2006 $0.78(0.40-0.97)$

Negaard et al. $2006 \quad 0.98(0.82-1.00)$

Seiderer et al. $2007 \quad 0.71(0.29-0.96)$

Lee et al. $2009 \quad 0.91(0.41-1.00)$

Gallego et al. $2011 \quad 0.80(0.28-0.99)$

Giusti et al. $2010 \quad 0.97(0.76-1.00)$

Hyun et al. $2011 \quad 0.87(0.60-0.98)$

Jensen et al. 2011 (1) $\quad 0.86(0.74-0.94)$

Oto $0.80(0.44-0.97)$

Wiarda et al. $2012 \quad 0.89(0.67-0.99)$

Adamek et al. $2012 \quad 0.93(0.80-0.98)$

Castiglione et al. $2013 \quad 0.95(0.89-0.98)$

Fallis et al.2013 $0.94(0.73-1.00)$

Kumar et al. $2015 \quad 0.17(0.00-0.64)$

$0.93(0.81-0.99)$

Pooled specificity $=0.88(0.84$ to 0.91$)$

$\chi^{2}=55.11 ; \mathrm{df}=18(p=0.0000)$

Sensitivity (95\% CI)

FIGURE 1: Sensitivity and specificity for active Crohn's disease (all studies).

stenosis (Figure 4) [9, 27-29, 34, 36, 37]. Pooled sensitivity was 0.65 (95\% CI 0.53 to 0.76 ) and pooled specificity was 0.93 (95\% CI 0.89 to 0.96 ).

\section{Discussion}

Our study represents the largest systematic review (in terms of patients and number of studies) of MR imaging for the detection of small bowel activity in Crohn's disease. Like previous studies and reviews, we demonstrate that MR imaging possesses high sensitivity and specificity in detecting small bowel activity $[3,9,10]$. Along with a relatively high positive likelihood ratio and relatively low negative likelihood ratio, it can be used in combination with pretest probabilities to determine small bowel activity in the appropriate clinical setting. The results from this meta-analysis are similar to those previously reported [9]. Of note, many of the studies differ from those included in previous reviews, not only because we focused only on the small bowel, but also because we included both studies with per-patient and per-segment analysis (though only per-patient analysis was pooled). Additionally, differences in response rates in regard to contacting authors likely explain the discrepancy in studies included in our review as compared to others. 


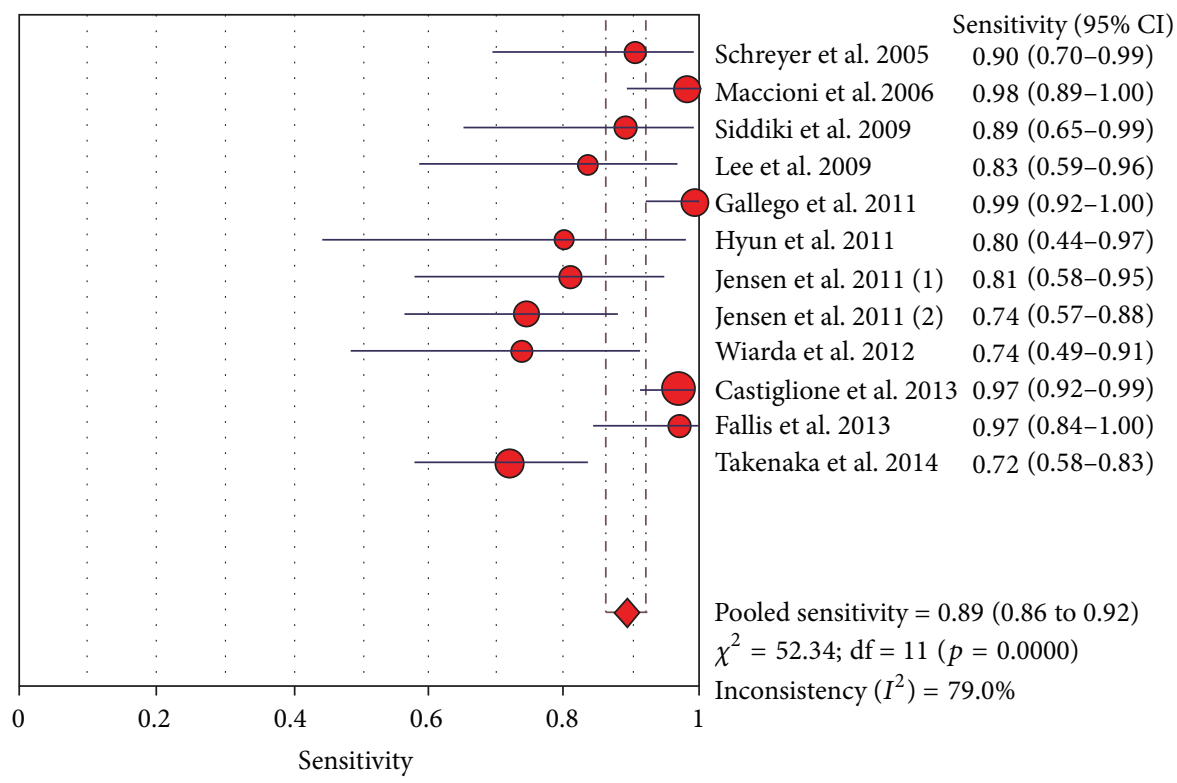

(a)

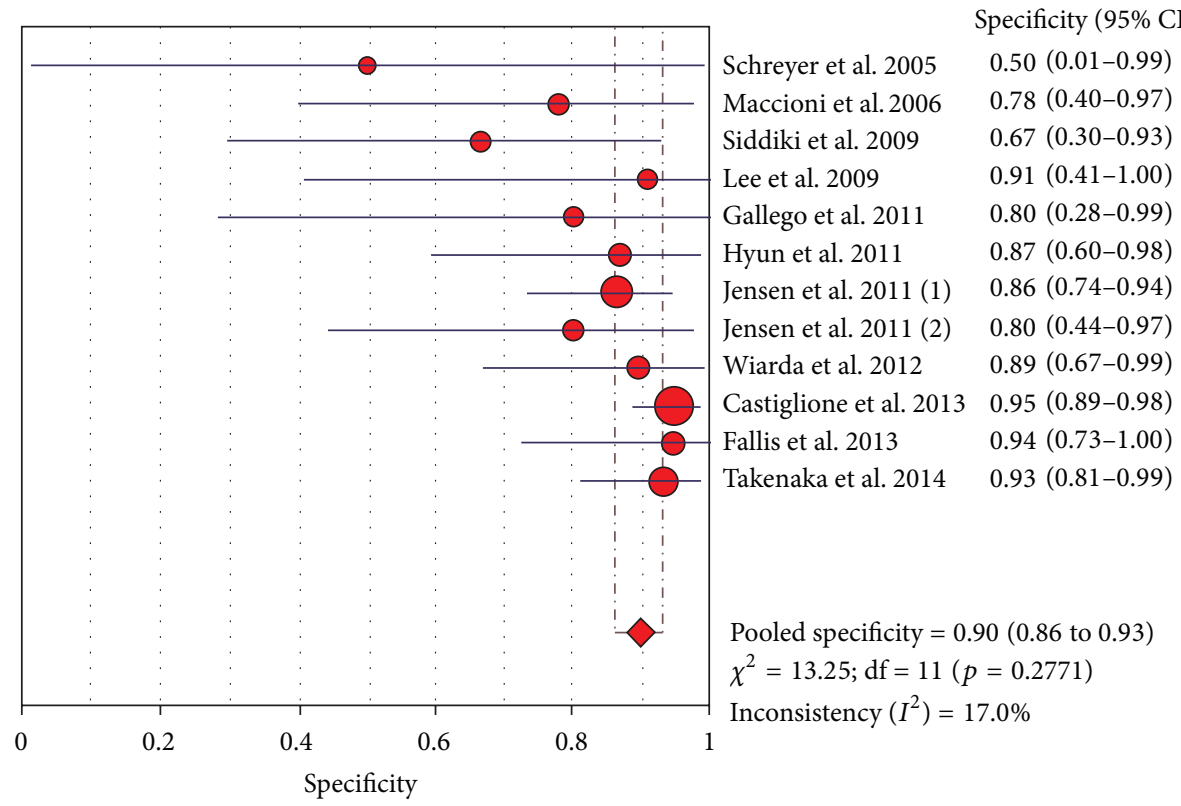

(b)

FIGURE 2: Sensitivity and specificity for active Crohn's disease (prospective studies only).

One of the many research areas in MR imaging is the use of enteroclysis in inflammatory bowel disease. Enteroclysis has been proposed to provide better small bowel distension because the contrast is provided directly through nasojejunal intubation rather than orally [40]. The limitations of enteroclysis are that it is not as widely available, requires fluoroscopic insertion of a nasojejunal tube (thus exposing patients to radiation), and is less well tolerated by patients [41]. A subgroup analysis of studies using enteroclysis did not demonstrate higher sensitivity and specificity. Similarly, Negaard et al. directly compared use of oral contrast and enteroclysis and also did not find any significant difference
[19]. One explanation for the lack of increment benefit of enteroclysis is because small bowel Crohn's disease usually affects the terminal ileum distally, rather than proximally, where the advantages of enteroclysis are more apparent. Overall, enteroclysis has not yet been shown to have any significant difference in diagnostic accuracy, and its role in Crohn's patients is still uncertain. Further study is warranted in determining potential benefits of enteroclysis in Crohn's disease proximal to the ileum.

In regard to intra- and extraluminal complications such as fistulas, abscesses, and stenosis, MR has been theorized to be the gold standard, since ileocolonoscopy can only 


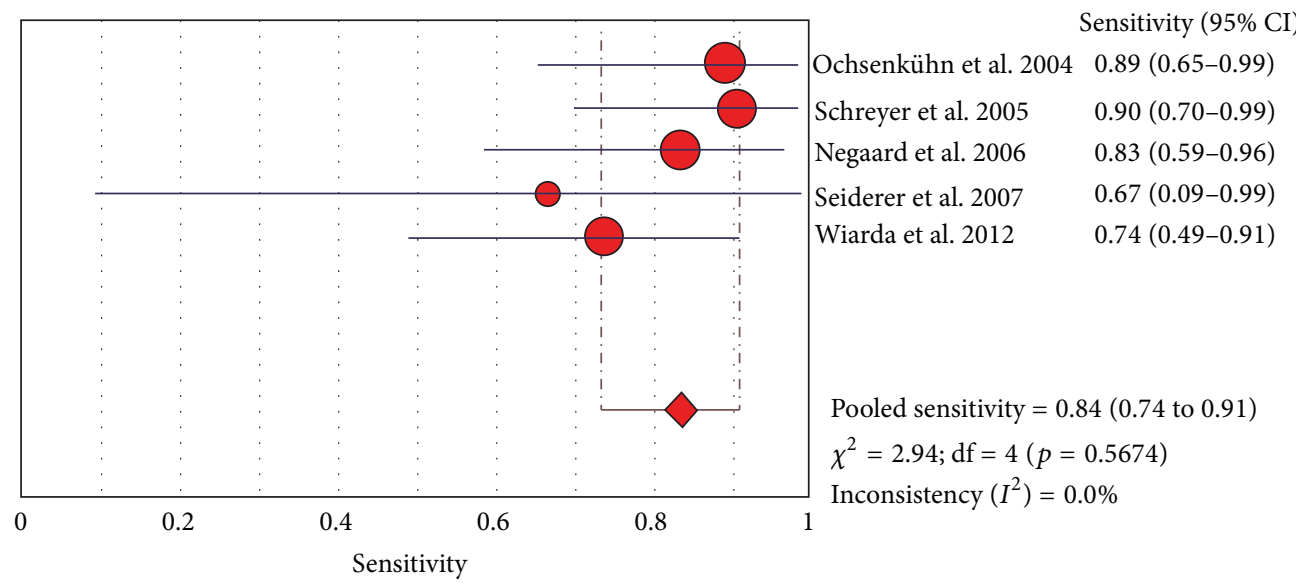

(a)

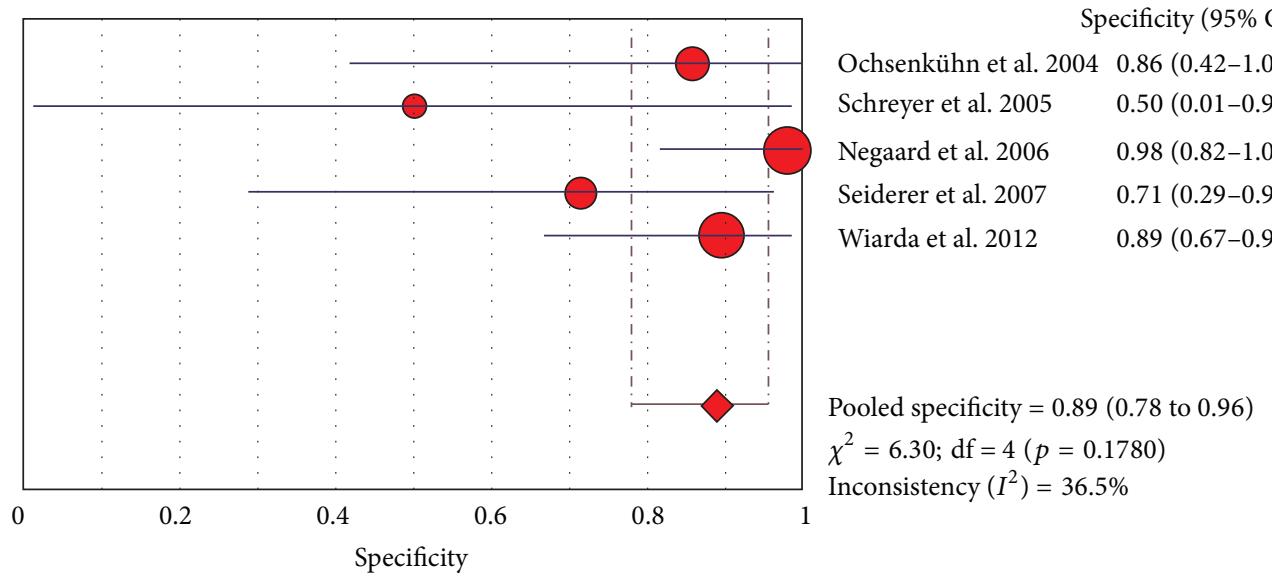

(b)

FIgURE 3: Sensitivity and specificity for active Crohn's disease (enteroclysis studies only).

assess luminal disease, and surgery is too invasive and not a feasible diagnostic modality. Our analysis revealed fairly high specificity in detecting stenosis, but only moderate sensitivity. However, our analysis was limited due to the small number of studies included. Previous studies looking at both small and large bowel have shown relatively high detection rates for stenosis $[26,42]$. Nevertheless, a metaanalysis by Qiu et al. showed that CT imaging may be better at detecting fistulas and stenosis. However, the results were not statistically significant, and the sensitivities and specificities were comparable to more recently published studies $[43,44]$. No differences were noted in detecting abscesses. The results for pooled analysis by Qiu et al. for stenosis revealed similar numbers to our study (sensitivity 65.3\%, specificity 94.4\%).

Current European guidelines recommend MR, US, and CT enterography or enteroclysis for the detection of intestinal involvement and penetrating lesions in CD. Additionally, the use of small bowel follow-through or small bowel enteroclysis is acceptable for detection of stenosis. They are also the recommended techniques for detection of extramural complications of CD $[1,45]$. American guidelines are less specific but do include the use of MR, amongst a multitude of other imaging modalities, to delineate and discriminate intra-abdominal masses/abscesses and in the evaluation of small bowel pathology in patients with CD [46].

One of the difficulties in replacing the gold standard with MR imaging is the lack of standardization of the imaging signs suggestive of active disease, especially with the growing number of sequences available. Previous studies have demonstrated that the most accurate signs of inflammation for MR were wall enhancement, mucosal lesions, and wall T2 hyperintensity $[39,47]$. In one study, Maccioni et al. looked at the difference using T1- versus T2-weighted imaging. They found that $\mathrm{T} 2$-weighted images provided greater sensitivity and specificity in diagnosing ileal lesions [17]. Additionally, a study by Udayasankar et al. found similar results in both the small and large bowel [48]. Previous studies have also found that sequences using diffusion-weighted imaging had high sensitivity and specificity $[30,49,50]$. Recently, there have been development of validated scoring systems including the MaRIA (Magnetic Resonance Index of Activity) score for assessment of disease activity and severity, the Lemann score, or the Crohn's Disease Digestive Damage Score, which takes into account many factors (clinical, endoscopic, and imaging findings) and attempts to measure cumulative damage [51, 52]. 


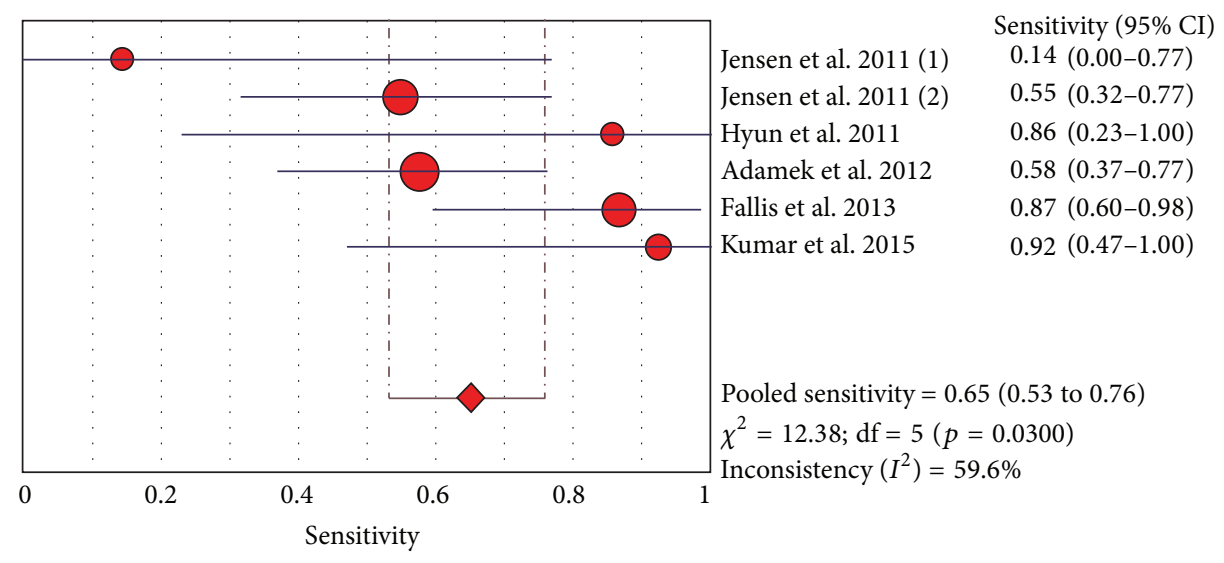

(a)

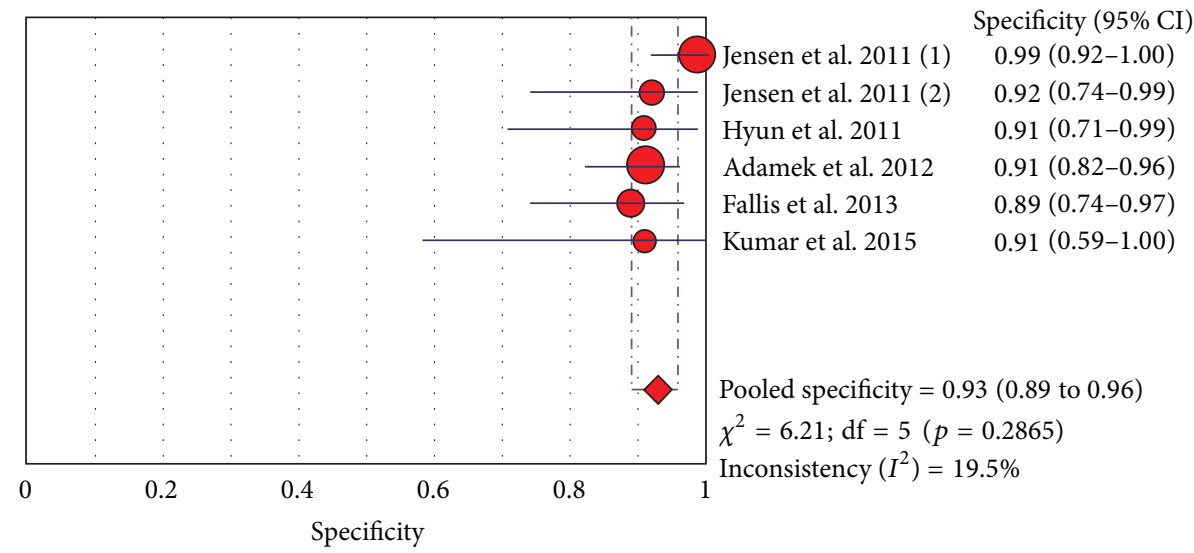

(b)

Figure 4: Sensitivity and specificity for stenosis in Crohn's disease (all studies).

An important consideration is whether the results of MR imaging change clinician management. A study by Mendoza et al. showed that MR helped in decision-making in more than half of patients, especially those involving the use of biological therapies and surgery [53]. Messaris et al. showed that $69 \%$ of patients had changes to medical and/or surgical management after clinicians were given MR imaging results [54]. Similar results have shown that MR findings influence surgical approaches to managing Crohn's patients [55].

Some of the limitations of our study include the varied length of time between the reference standard and MR imaging. Since clinical activity can change quite drastically, especially with the use of medications, some of the results might have been inaccurate in determining disease activity. Secondly, since we used per-patient data, we were not able to differentiate severity in regard to determining small bowel activity. Other studies have suggested that MRI has good correlation with Crohn's severity indices [56]. Similarly, we were unable to perform per-segment analysis which might have led to an overestimation of the accuracy of MR imaging. This is likely due to the use of endoscopy as a reference standard and its inadequacy in assessing more proximal small bowel. Other limitations include the fact that we were only able to analyse one complication (stenosis), and that others (such as abscess and fistulas) are not well visualized on endoscopy. Similarly, due to the small number of studies, we were not able to determine whether more advanced MR (such as MR with 3.0 T magnetic field strength) had any additional benefit. Finally, the large heterogeneity amongst the studies, including reference standards, radiologists experience, and results, suggests that more definitive studies might still be required. Sources of heterogeneity include inclusion of studies of different sample size and different criteria for disease activity, as well as inclusion of studies using different MR enterography/enteroclysis protocols (including different magnetic field strengths, oral contrast, and radiologist experience).

In regard to other modalities of imaging, many studies assessed the use of ultrasound and computed tomography. The benefit of ultrasound is that it does not involve ionizing radiation and is relatively inexpensive [3]. Previous studies assessing ultrasound have demonstrated high sensitivities and specificities. There is one large-scale trial comparing US and MR currently in progress: the UK-based MR Enterography or Ultrasound in Crohn's disease (METRIC) trial $[3,57]$. The use of US is thought to be limited by operator-experience; however MR has also been shown to have interobserver variability. However, the use of scoring systems such as 
MaRIA has been proven to improve interobserver agreement [58]. Similarly, one meta-analysis has shown similar accuracy between CT and MR. CT has the benefit of being widely available and cost-effective. It, however, also carries the risk of ionizing radiation, especially amongst patients who might require multiple scans throughout the course of their life-long disease [43].

In conclusion, MR imaging provides a reliable alternative to ileocolonoscopy in detecting small bowel activity in patients with Crohn's disease. Its advantages include high diagnostic accuracy, favorable safety profile, and the ability to assess intra- and extraluminal complications. Its disadvantages include high cost and limited availability. Nevertheless, with the rapid expansion in MR accessibility, it will likely play a greater role in the future in both the diagnosis and management of patients with Crohn's disease.

\section{Competing Interests}

The authors declare that they have no competing interests.

\section{Authors' Contributions}

Osman Ahmed and Geoffrey C. Nguyen conceived the study. Osman Ahmed and David Mario Rodrigues reviewed the literature search. Osman Ahmed conducted the metaanalysis and drafted the paper. Geoffrey C. Nguyen reviewed the data and all authors critically reviewed the paper.

\section{References}

[1] G. Van Assche, A. Dignass, J. Panes et al., "The second European evidence-based consensus on the diagnosis and management of Crohn's disease: definitions and diagnosis," Journal of Crohn's and Colitis, vol. 4, no. 1, pp. 7-27, 2010.

[2] H. J. Steinhardt, K. Loeschke, H. Kasper, K. H. Holtermüller, and H. Schäfer, "European Cooperative Crohn's Disease Study (ECCDS): clinical features and natural history," Digestion, vol. 31, no. 2-3, pp. 97-108, 1985.

[3] J. Panés, R. Bouzas, M. Chaparro et al., "Systematic review: the use of ultrasonography, computed tomography and magnetic resonance imaging for the diagnosis, assessment of activity and abdominal complications of Crohn's disease," Alimentary Pharmacology \& Therapeutics, vol. 34, no. 2, pp. 125-145, 2011.

[4] L. C. Cirillo, L. Camera, M. Della Noce, F. Castiglione, G. Mazzacca, and M. Salvatore, "Accuracy of enteroclysis in Crohn's disease of the small bowel: a retrospective study," European Radiology, vol. 10, no. 12, pp. 1894-1898, 2000.

[5] K. Van Gemert-Horsthuis, J. Florie, D. W. Hommes et al., "Feasibility of evaluating Crohn's disease activity at 3.0 Tesla," Journal of Magnetic Resonance Imaging, vol. 24, no. 2, pp. 340348, 2006.

[6] J. M. Peloquin, D. S. Pardi, W. J. Sandborn et al., "Diagnostic ionizing radiation exposure in a population-based cohort of patients with inflammatory bowel disease," American Journal of Gastroenterology, vol. 103, no. 8, pp. 2015-2022, 2008.

[7] F. Dambha, J. Tanner, and N. Carroll, "Diagnostic imaging in Crohn's disease: what is the new gold standard?" Best Practice and Research: Clinical Gastroenterology, vol. 28, no. 3, pp. 421436, 2014.
[8] G. Masselli and G. Gualdi, "MR imaging of the small bowel," Radiology, vol. 264, no. 2, pp. 333-348, 2012.

[9] L. M. Wu, J. R. Xu, H. Y. Gu, J. Hua, and J. Hu, "Is magnetic resonance imaging a reliable diagnostic tool in the evaluation of active Crohn's disease in the small bowel?" Journal of Clinical Gastroenterology, vol. 47, no. 4, pp. 328-338, 2013.

[10] K. Horsthuis, S. Bipat, P. C. F. Stokkers, and J. Stoker, "Magnetic resonance imaging for evaluation of disease activity in Crohn's disease: a systematic review," European Radiology, vol. 19, no. 6, pp. 1450-1460, 2009.

[11] P. F. Whiting, A. W. S. Rutjes, M. E. Westwood et al., "Quadas-2: a revised tool for the quality assessment of diagnostic accuracy studies," Annals of Internal Medicine, vol. 155, no. 8, pp. 529-536, 2011.

[12] D. M. Koh, Y. Miao, R. J. S. Chinn et al., "MR imaging evaluation of the activity of Crohn's disease," American Journal of Roentgenology, vol. 177, no. 6, pp. 1325-1332, 2001.

[13] A. Rieber, D. Wruk, S. Potthast et al., "Diagnostic imaging in Crohn's disease: comparison of magnetic resonance imaging and convertional imaging methods," International Journal of Colorectal Disease, vol. 15, no. 3, pp. 176-181, 2000.

[14] T. Ochsenkühn, K. Herrmann, S. O. Schoenberg, M. F. Reiser, B. Göke, and M. Sackmann, "Crohn disease of the small bowel proximal to the terminal ileum: detection by MR-enteroclysis," Scandinavian Journal of Gastroenterology, vol. 39, no. 10, pp. 953-960, 2004.

[15] M. Pascu, A. B. Rownowski, H.-P. Müller, A. Adler, B. Wiedenmann, and A. U. Dignass, "Clinical relevance of transabdominal ultrasonography and magnetic resonance imaging in patients with inflammatory bowel disease of the terminal ileum and large bowel," Inflammatory Bowel Diseases, vol. 10, no. 4, pp. 373-382, 2004.

[16] A. G. Schreyer, H. C. Rath, R. Kikinis et al., "Comparison of magnetic resonance imaging colonography with conventional colonoscopy for the assessment of intestinal inflammation in patients with inflammatory bowel disease: a feasibility study," Gut, vol. 54, no. 2, pp. 250-256, 2005.

[17] F. Maccioni, A. Bruni, A. Viscido et al., "MR imaging in patients with Crohn disease: value of T2- versus T1-weighted gadolinium-enhanced MR sequences with use of an oral superparamagnetic contrast agent," Radiology, vol. 238, no. 2, pp. 517530, 2006.

[18] A. Negaard, L. Sandvik, A. Mulahasanovic, A. E. Berstad, and N.-E. Klöw, "Magnetic resonance enteroclysis in the diagnosis of small-intestinal Crohn's disease: diagnostic accuracy and inter- and intra-observer agreement," Acta Radiologica, vol. 47, no. 10, pp. 1008-1016, 2006.

[19] A. Negaard, V. Paulsen, L. Sandvik et al., "A prospective randomized comparison between two MRI studies of the small bowel in Crohn's disease, the oral contrast method and MR enteroclysis," European Radiology, vol. 17, no. 9, pp. 2294-2301, 2007.

[20] J. Seiderer, K. Herrmann, H. Diepolder et al., "Double-balloon enteroscopy versus magnetic resonance enteroclysis in diagnosing suspected small-bowel Crohn's disease: results of a pilot study," Scandinavian Journal of Gastroenterology, vol. 42, no. 11, pp. 1376-1385, 2007.

[21] H. A. Siddiki, J. L. Fidler, J. G. Fletcher et al., "Prospective comparison of state-of-the-art MR enterography and CT enterography in small-bowel Crohn's disease," American Journal of Roentgenology, vol. 193, no. 1, pp. 113-121, 2009. 
[22] S. S. Lee, A. Y. Kim, S.-K. Yang et al., "Crohn disease of the small bowel: comparison of CT enterography, MR enterography, and small-bowel follow-through as diagnostic techniques," Radiology, vol. 251, no. 3, pp. 751-761, 2009.

[23] J. C. Gallego, A. I. Echarri, A. Porta, and V. Ollero, "Ileal Crohn's disease: MRI with endoscopic correlation," European Journal of Radiology, vol. 80, no. 2, pp. e8-e12, 2011.

[24] S. Giusti, L. Faggioni, E. Neri et al., "Dynamic MRI of the small bowel: usefulness of quantitative contrast-enhancement parameters and time-signal intensity curves for differentiating between active and inactive Crohn's disease," Abdominal Imaging, vol. 35, no. 6, pp. 646-653, 2010.

[25] C. A. Parisinos, V. E. D. McIntyre, T. Heron et al., "Magnetic resonance follow-through imaging for evaluation of disease activity in ileal Crohn's Disease: an Observational, Retrospective cohort Study," Inflammatory Bowel Diseases, vol. 16, no. 7, pp. 1219-1226, 2010.

[26] G. Fiorino, C. Bonifacio, L. Peyrin-Biroulet et al., "Prospective comparison of computed tomography enterography and magnetic resonance enterography for assessment of disease activity and complications in ileocolonic Crohn's disease," Inflammatory Bowel Diseases, vol. 17, no. 5, pp. 1073-1080, 2011.

[27] S. B. Hyun, Y. Kitazume, M. Nagahori et al., "Magnetic resonance enterocolonography is useful for simultaneous evaluation of small and large intestinal lesions in Crohn's disease," Inflammatory Bowel Diseases, vol. 17, no. 5, pp. 1063-1072, 2011.

[28] M. D. Jensen, T. Nathan, S. R. Rafaelsen, and J. Kjeldsen, "Diagnostic accuracy of capsule endoscopy for small bowel Crohn's disease is superior to that of MR enterography or CT enterography," Clinical Gastroenterology and Hepatology, vol. 9, no. 2, pp. 124-129, 2011.

[29] M. D. Jensen, J. Kjeldsen, S. R. Rafaelsen, and T. Nathan, "Diagnostic accuracies of MR enterography and CT enterography in symptomatic Crohn's disease," Scandinavian Journal of Gastroenterology, vol. 46, no. 12, pp. 1449-1457, 2011.

[30] A. Oto, A. Kayhan, J. T. B. Williams et al., "Active Crohn's disease in the small bowel: evaluation by diffusion weighted imaging and quantitative dynamic contrast enhanced MR imaging," Journal of Magnetic Resonance Imaging, vol. 33, no. 3, pp. 615624, 2011.

[31] B. M. Wiarda, P. B. F. Mensink, D. G. N. Heine et al., "Small bowel Crohn's disease: MR enteroclysis and capsule endoscopy compared to balloon-assisted enteroscopy," Abdominal Imaging, vol. 37, no. 3, pp. 397-403, 2012.

[32] C. Friedrich, A. Fajfar, M. Pawlik et al., "Magnetic resonance enterography with and without biphasic contrast agent enema compared to conventional ileocolonoscopy in patients with Crohn's disease," Inflammatory Bowel Diseases, vol. 18, no. 10, pp. 1842-1848, 2012.

[33] D. J. Grand, V. Kampalath, A. Harris et al., "MR enterography correlates highly with colonoscopy and histology for both distal ileal and colonic Crohn's disease in 310 patients," European Journal of Radiology, vol. 81, no. 5, pp. e763-e769, 2012.

[34] H. E. Adamek, W. Schantzen, U. Rinas, M. Goyen, W. Ajaj, and C. Esser, "Ultra-high-field magnetic resonance enterography in the diagnosis of ileitis (Neo-)terminalis: a prospective study," Journal of Clinical Gastroenterology, vol. 46, no. 4, pp. 311-316, 2012.

[35] F. Castiglione, P. P. Mainenti, G. D. De Palma et al., "Noninvasive diagnosis of small bowel Crohn's disease: direct comparison of bowel sonography and magnetic resonance enterography," Inflammatory Bowel Diseases, vol. 19, no. 5, pp. 991-998, 2013.
[36] S. A. Fallis, P. Murphy, R. Sinha et al., "Magnetic resonance enterography in Crohn's disease: a comparison with the findings at surgery," Colorectal Disease, vol. 15, no. 10, pp. 1273-1280, 2013.

[37] S. Kumar, A. Hakim, C. Alexakis et al., "Small intestinal contrast ultrasonography for the detection of small bowel complications in Crohn's disease: correlation with intraoperative findings and magnetic resonance enterography," Journal of Gastroenterology and Hepatology, vol. 30, no. 1, pp. 86-91, 2015.

[38] K. Takenaka, K. Ohtsuka, Y. Kitazume et al., "Comparison of magnetic resonance and balloon enteroscopic examination of the small intestine in patients with Crohn's disease," Gastroenterology, vol. 147, no. 2, pp. 334-342.e3, 2014.

[39] P. Church, D. Turner, T. Walters, M. L. Greer, M. Amitai, and A. Griffiths, "A systematic review of MR enterography signs of inflammation and damage in Crohn's disease," Journal of Crohn's and Colitis, vol. 6, supplement 1, p. S84, 2012.

[40] N. Gourtsoyiannis, N. Papanikolaou, J. Grammatikakis, and P. Prassopoulos, "MR enteroclysis: technical considerations and clinical applications," European Radiology, vol. 12, no. 11, pp. 2651-2658, 2002.

[41] I. C. Lawrance, C. J. Welman, P. Shipman, and K. Murray, "Small bowel MRI enteroclysis or follow through: which is optimal?" World Journal of Gastroenterology, vol. 15, no. 42, pp. 5300-5306, 2009.

[42] F. Lenze, J. Wessling, J. Bremer et al., "Detection and differentiation of inflammatory versus fibromatous Crohn's disease strictures: prospective comparison of 18F-FDG-PET/CT, MR-enteroclysis, and transabdominal ultrasound versus endoscopic/histologic evaluation," Inflammatory Bowel Diseases, vol. 18, no. 12, pp. 2252-2260, 2012.

[43] Y. Qiu, R. Mao, B.-L. Chen et al., "Systematic review with meta-analysis: magnetic resonance enterography vs. computed tomography enterography for evaluating disease activity in small bowel Crohn's disease," Alimentary Pharmacology and Therapeutics, vol. 40, no. 2, pp. 134-146, 2014.

[44] C. Papadia, E. Maffei, P. Del Rio et al., "Sensitivity and specificity of magnetic resonance enterography in the clinical management of fistulizing Crohn's disease," Inflammatory Bowel Diseases, vol. 19, no. 9, pp. 1896-1903, 2013.

[45] J. Panes, Y. Bouhnik, W. Reinisch et al., "Imaging techniques for assessment of inflammatory bowel disease: joint ECCO and ESGAR evidence-based consensus guidelines," Journal of Crohn's and Colitis, vol. 7, no. 7, pp. 556-585, 2013.

[46] GR. Lichtenstein, S. B. Hanauer, and W. J. Sandborn, "Management of Crohn's disease in adults," The American Journal of Gastroenterology, vol. 104, no. 2, pp. 465-483, 2009.

[47] A. Lasocki, A. Pitman, R. Williams, B. Lui, A. V. Kalade, and S. Farish, "Relative efficacy of different MRI signs in diagnosing active Crohn's disease, compared against a histological gold standard," Journal of Medical Imaging and Radiation Oncology, vol. 55, no. 1, pp. 11-19, 2011.

[48] U. K. Udayasankar, D. Martin, T. Lauenstein et al., "Role of spectral presaturation attenuated inversion-recovery fatsuppressed T2-weighted MR imaging in active inflammatory bowel disease," Journal of Magnetic Resonance Imaging, vol. 28, no. 5, pp. 1133-1140, 2008.

[49] J. A. W. Tielbeek, M. L. W. Ziech, Z. Li et al., "Evaluation of conventional, dynamic contrast enhanced and diffusion weighted MRI for quantitative Crohn's disease assessment with histopathology of surgical specimens," European Radiology, vol. 24, no. 3, pp. 619-629, 2014. 
[50] A. Oussalah, V. Laurent, O. Bruot et al., "Diffusion-weighted magnetic resonance without bowel preparation for detecting colonic inflammation in inflammatory bowel disease," Gut, vol. 59, no. 8, pp. 1056-1065, 2010.

[51] B. Pariente, J. Cosnes, S. Danese et al., "Development of the Crohn's disease digestive damage score, the Lémann score," Inflammatory Bowel Diseases, vol. 17, no. 6, pp. 1415-1422, 2011.

[52] J. Rimola, S. Rodriguez, O. García-Bosch et al., "Magnetic resonance for assessment of disease activity and severity in ileocolonic Crohn's disease," Gut, vol. 58, no. 8, pp. 1113-1120, 2009.

[53] J. L. Mendoza, Y. González-Lama, C. Taxonera et al., "Using of magnetic resonance enterography in the management of crohn's disease of the small intestine: first year of experience," Revista Espanola de Enfermedades Digestivas, vol. 104, no. 11, pp. 578583, 2012.

[54] E. Messaris, N. Chandolias, D. Grand, and V. Pricolo, "Role of magnetic resonance enterography in the management of Crohn disease," Archives of Surgery, vol. 145, no. 5, pp. 471-475, 2010.

[55] A. Spinelli, G. Fiorino, P. Bazzi et al., "Preoperative magnetic resonance enterography in predicting findings and optimizing surgical approach in Crohn's disease," Journal of Gastrointestinal Surgery, vol. 18, no. 1, pp. 83-91, 2014.

[56] J. Florie, K. Horsthuis, D. W. Hommes et al., "Magnetic resonance imaging compared with ileocolonoscopy in evaluating disease severity in Crohn's disease," Clinical Gastroenterology and Hepatology, vol. 3, no. 12, pp. 1221-1228, 2005.

[57] S. Taylor, S. Mallett, G. Bhatnagar et al., "METRIC (MREnterography or ulTRasound in Crohn's disease): a study protocol for a multicentre, non-randomised, single-arm, prospective comparison study of magnetic resonance enterography and small bowel ultrasound compared to a reference standard in those aged 16 and over," BMC Gastroenterology, vol. 14, no. 1, article 142, 2014.

[58] A. Buisson, A. Joubert, P. F. Montoriol et al., "Diffusion-weighted magnetic resonance imaging for detecting and assessing ileal inflammation," Alimentary Pharmacology \& Therapeutics, vol. 37, no. 5, pp. 537-545, 2013. 


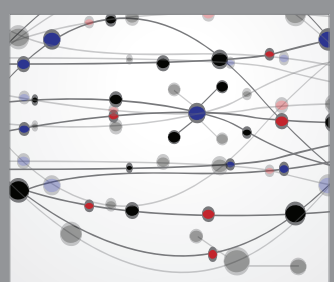

The Scientific World Journal
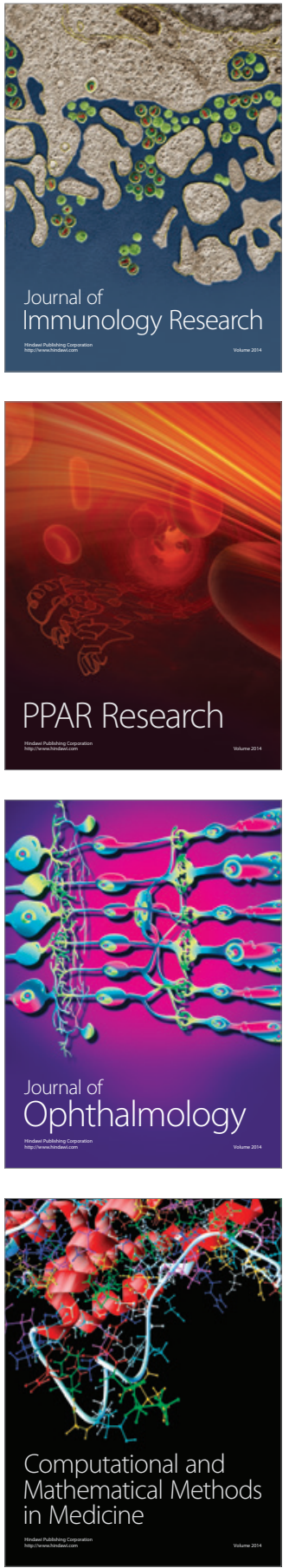

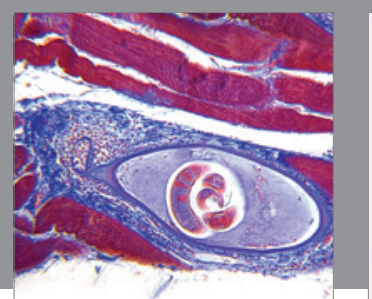

Gastroenterology Research and Practice

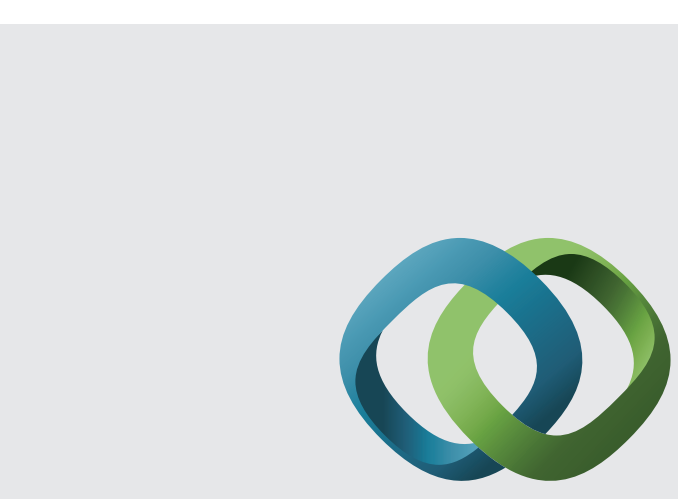

\section{Hindawi}

Submit your manuscripts at

http://www.hindawi.com
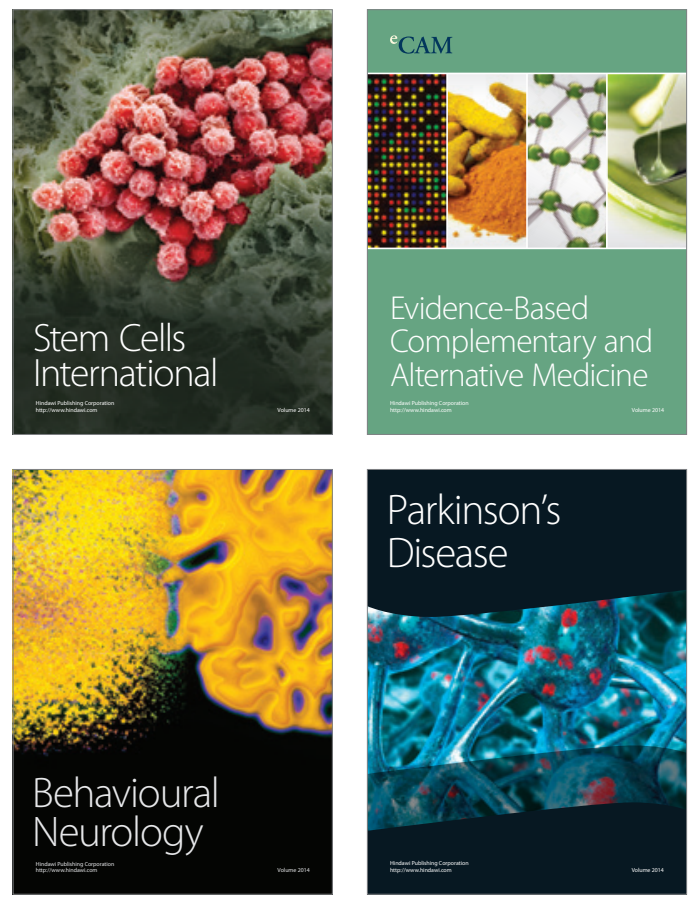
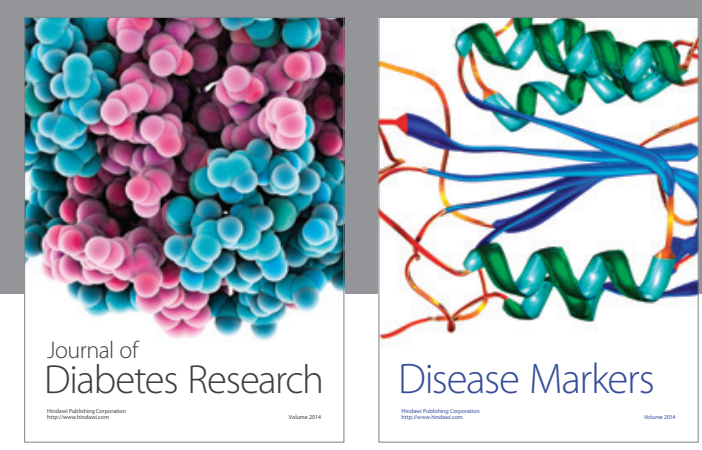

Disease Markers
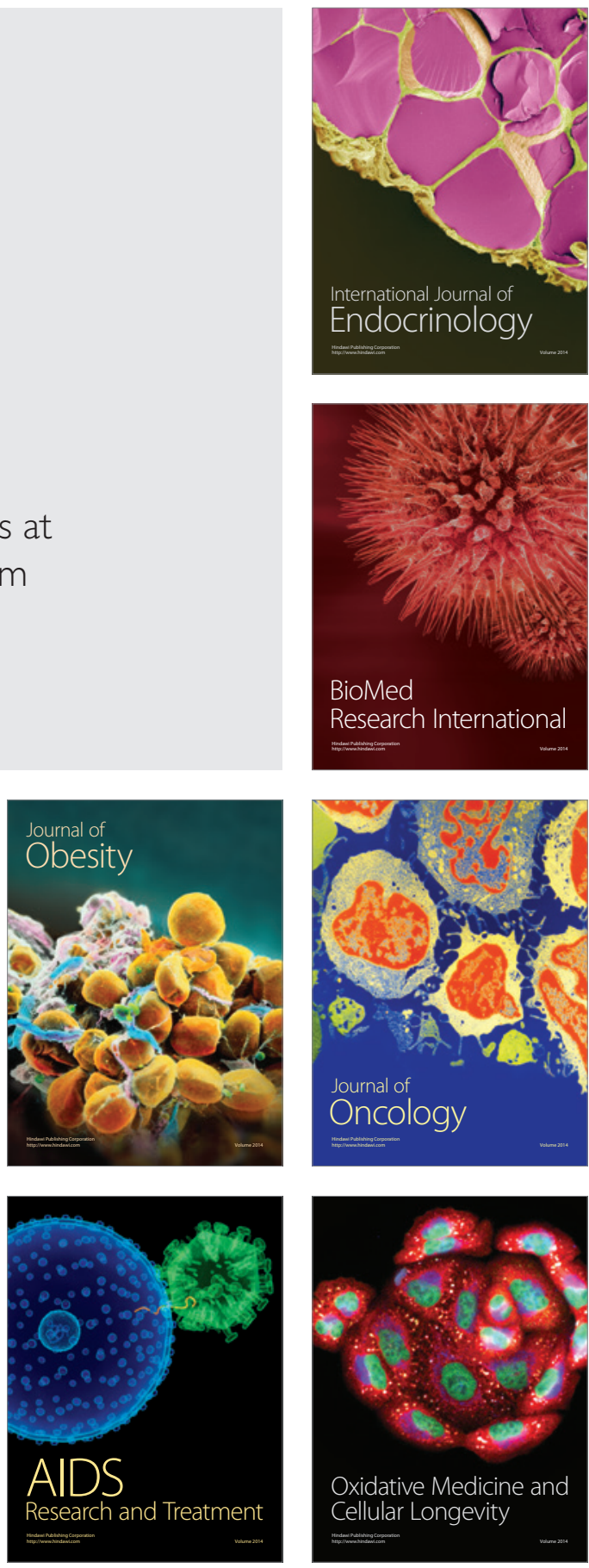